\title{
A Smart e-Form for Effective Business Communication in the Financial Industry
}

\author{
Hyejung Chang ${ }^{1}$, Mikyung Park ${ }^{2}$ \\ ${ }^{1}$ School of Management, Kyung Hee University, Seoul, Korea \\ ${ }^{2}$ FORCS, Seoul, Korea
}

Objectives: Smart e-Forms are a new form of technology that converts complex paperwork to digital forms in an enterprise setting. In the context of the rapidly changing communication channels brought by the move toward a digital innovation environment in the financial industry, this paper examines a smart e-Form solution that can aid effective business communication.

Methods: Financial services using smart e-Forms are developing multilaterally with the use of electronic documents in both faceto-face and non-face-to-face channels. The electronic document system for enhancing competitiveness in face-to-face environments includes PPR (paperless and process reconstruction) and tablet banking systems, while the distance contract system through mobile banking can be utilized in non-face-to-face environments.

Results: As a functional document format that includes business logic, smart e-Forms allow various types of data input such as photos, voice recordings, barcode scanning, and e-Signatures through the use of smart devices. This technology has been utilized in implementing paperless services, tablet banking, and distance contract systems for a number of financial institutions, and e-Form technology is being optimized for the latest mobile devices in response to the demands of the financial market.

Conclusions: The rapid development of smart e-Form technology has played a major role in innovation in the financial sector. This technology improves customer convenience and work efficiency for a diversified financial environment, and the e-Form-based financial service system is becoming more competitive in various ways to lead the Fourth Industrial Revolution.

Key Words: Digital Communication, Electronic Document, Paperless Service, Tablet Banking, Distance Contract

\section{Introduction}

In the era of the Fourth Industrial Revolution, industries are moving forward to prepare countermeasures in response to changes in the digital environment, and the financial industry,

Received: Jun 25, 2018 Revised: Jul 12, 2018 Accepted: Jul 18, 2018 Corresponding author: Hyejung Chang School of Management, Kyung Hee University, 26 Kyungheedae-ro, Dongdaemun-gu, Seoul 02447, Korea

Tel: +82-2-961-9432, E-mail: hjchang@khu.ac.kr

This is an Open Access article distributed under the terms of the Creative Commons Attribution Non-Commercial License (http://creativecommons.org/licenses/ by-nc/4.0/) which permits unrestricted non-commercial use, distribution, and reproduction in any medium, provided the original work is properly cited.

Copyright $\odot 2018$ Korean Association for Business Communication. which is relatively conservative compared to other industries, is no exception (Dasho, Meka, Sharko, \& Baholli, 2016). With the rapid growth of social network services (SNS) and customer smartphone use, financial services based on digital technology are emerging to support or replace traditional financial services (Dapp, 2015). Recently, many financial institutions have referred to "digital innovation" as a business strategy, and they are showing their willingness to make enterprise-wide changes to digital transition through actions such as improving mobile banking systems and offering digital education to employees (Adobe Korea, 2018).

The executive chairman of the BBVA (Banco Bilbao Vizcaya Argentaria) Group, Francisco González, pointed out the dra- 
matic impact that technology is having on the financial sector and said that BBVA would be a software company in the future at the Mobile World Congress in 2015 (BBVA, 2015). He also said that " $50 \%$ of our customer base will be accessing us through digital channels this year" at the World Economic Forum in Davos, Switzerland in 2018 (BBVA, 2018). In Goldman Sachs, one of the world's largest investment banks, there are only two out of 600 equity traders left employed in their New York headquarters (Byrnes, 2017). Automated trading programs supported by 200 computer engineers have taken over the rest of the work, and today, nearly 45 percent of trading is done electronically. Recently, Goldman Sachs CFO Marty Chavez confirmed the dramatic shift taking place across Wall Street as technology touches everything from trading to investment banking (SciPol, 2017).

In Korea as well, the financial industry is undergoing innovative changes. For example, Citibank Korea announced plans to cut 101 out of 126 of their branches nationwide in April 2017 as a strategy that would strengthen digital financial transactions. After discussion between the labor and the management, they agreed to maintain 36 branches, but the shutdown of more than $70 \%$ of their branches has inevitably resulted in a large-scale workforce reduction. This means that Citibank Korea is effectively transforming into an "online bank" tailored to customer demands, where $95 \%$ of financial transactions are carried out through non-face-to-face channels (Jung, 2017; S. I. Lee, 2017). On the other hand, KEB Hana Bank has launched "HAI Banking," an interactive financial service based on AI. HAI Banking features AI chatbot, which allows users to sign up for products, exchange money, and inquire about assets through SNS, mobile messenger, etc. These changes are expected to be more convenient than current banking services because Chatbot would make it easy to send and receive money (S. I. Lee, 2018). In addition, competition for non-face-to-face channels is increasing due to the appearance of branchless banks such as Kakao Bank and K-bank (S. W. Lee, Song, \& Park, 2017).

The rapid development of smart e-Form technology has played a major role in innovation in the financial sector. In the past, e-Document systems were a system used to extract and utilize data by scanning paper documents. These systems are now, however, moving to offer the creation and use of e-Documents without paper from the beginning by combining new digital technologies. Smart e-Form is a technology used in enterprises that converts complex paperwork to digital forms.

The paperless trend is racing for the implementation of a "paperless society" around the world, and Korea has tried to remain ahead of this digital trend. Korea leads internationally in 4G LTE availability (97.5\%) among 88 countries according to OpenSignal.com (Opensignal, 2018), and mobile banking usage rates (47\%-55\%) are also at the top of many statistical sources (KPMG, 2015; Toit \& Burns, 2016). In particular, the use of e-Documents in the Korean financial system began to become popular with the enactment of the Law of Electronic Contract and Digital Signature at the beginning of 2012 and the Electronic Financial Transaction Act in 2016 (Bae \& Ryu, 2016), two laws that enabled the signing of insurance electronic contracts with mobile devices including tablet PCs. Today, with the rapid development of e-Documents, business innovation with even smarter functions is being made in financial sectors such as banks, securities firms, and credit card companies.

As described above, in the context of the rapidly changing communication channel of the financial industry in the digital innovation environment, this paper introduces the systems of a leading e-Document software company, FORCS (http://www. forcs.com/). FORCS has been engaged in implementing paperless services, tablet banking, and non-face-to-face contract service systems for a number of financial institutions. It also develops e-Document technology optimized for the latest mobile devices in response to the demands of financial markets.

\section{Case Description}

\section{Digital Banking Solutions Using Smart e-Forms}

The digitalization of the financial sector is progressing rapidly, and the conditions to survive in this sector are becoming increasingly smarter and more diverse. Therefore, to optimize the business processes of financial institutions, integrated communication channels using IT have developed, and smart e-Forms have emerged. Specifically, as a functional document format that includes business logic, smart e-Forms allow various types of data input such as photos, voice recordings, barcode scanning, and e-Signatures using smart devices. It is a mobile-based system that is linked with the company's main information system to create and process e-Documents anytime and anywhere.

The OZ e-Form of FORCS introduced in this paper is a representative solution of the smart e-Form, which leads the e-Document industry. It supports both existing PDF files and XML formats in one viewer and also provides a look and feel similar to those of real paper documents.

Smart e-Forms must meet the changing needs of financial consumers in the digital era. The relatively younger generation of smart consumers prefer non-face-to-face channels to judge themselves in financial transactions, while those in their 50s or older still prefer face-to-face channels. There is also a tendency that the more assets one has, the more one prefers face-to-face channels. Therefore, financial services are developing multilat- 
erally in both face-to-face and non-face-to-face channels. As shown in Figure 1, the e-Form utilization system for enhancing competitiveness in the face-to-face environment includes PPR (paperless and process reconstruction) and tablet banking systems, while the distance contract system through electronic signatures can proceed in a non-face-to-face environment.

\section{Paperless and Process Reconstruction System}

The first step toward going paperless has been done by digitization, but this change has been limited to a "simple change from analog to digital form" in which paper documents are converted into images by using a scanner and characters are read through text recognition. Therefore, there is still an inconvenience in business processes such as scanning documents and inputting the content of the document created by the customer. From the customers' point of view, these inconveniences also result in an increase in waiting time.

However, in the PPR system, the customer fills out a smart e-Form-based application form with a tablet and stylus. With a desktop monitor, the bank teller sees the same screen and helps the customer complete the application form through a real-time two-way communication channel. (Figure 2) This enables customers to apply for services, such as opening an account, im- mediately via an e-Form without filling out a paper application form at the counter. Inside the financial institution, the desktop $\mathrm{PC}$ at the counter is integrated with the legacy system and other information systems to complete transaction services in real time. This paperless system improves customer convenience and work efficiency and represents an adaptive, diversified financial environment.

\section{Tablet Banking System}

The tablet banking system acts as a smart branch to support business functions of financial transaction services wherever customers are located. It is a mobile system that is linked with financial institutions and can be used without the limitation of time and place. It can also scan ID cards by using the camera of a mobile device, thus enabling bank services such as opening a bank account, applying for a credit card or mortgage, or subscribing to financial investment products (e.g., funds). The tablet banking tool is provided to banking sales managers to perform efficiently and effectively. The process and the components of a tablet banking system are shown in Figure 3 .

In practice, tablet banking is blazing a trail in the financial industry, and most of the major banks in Korea have implemented this emerging financial technology. As an example, through

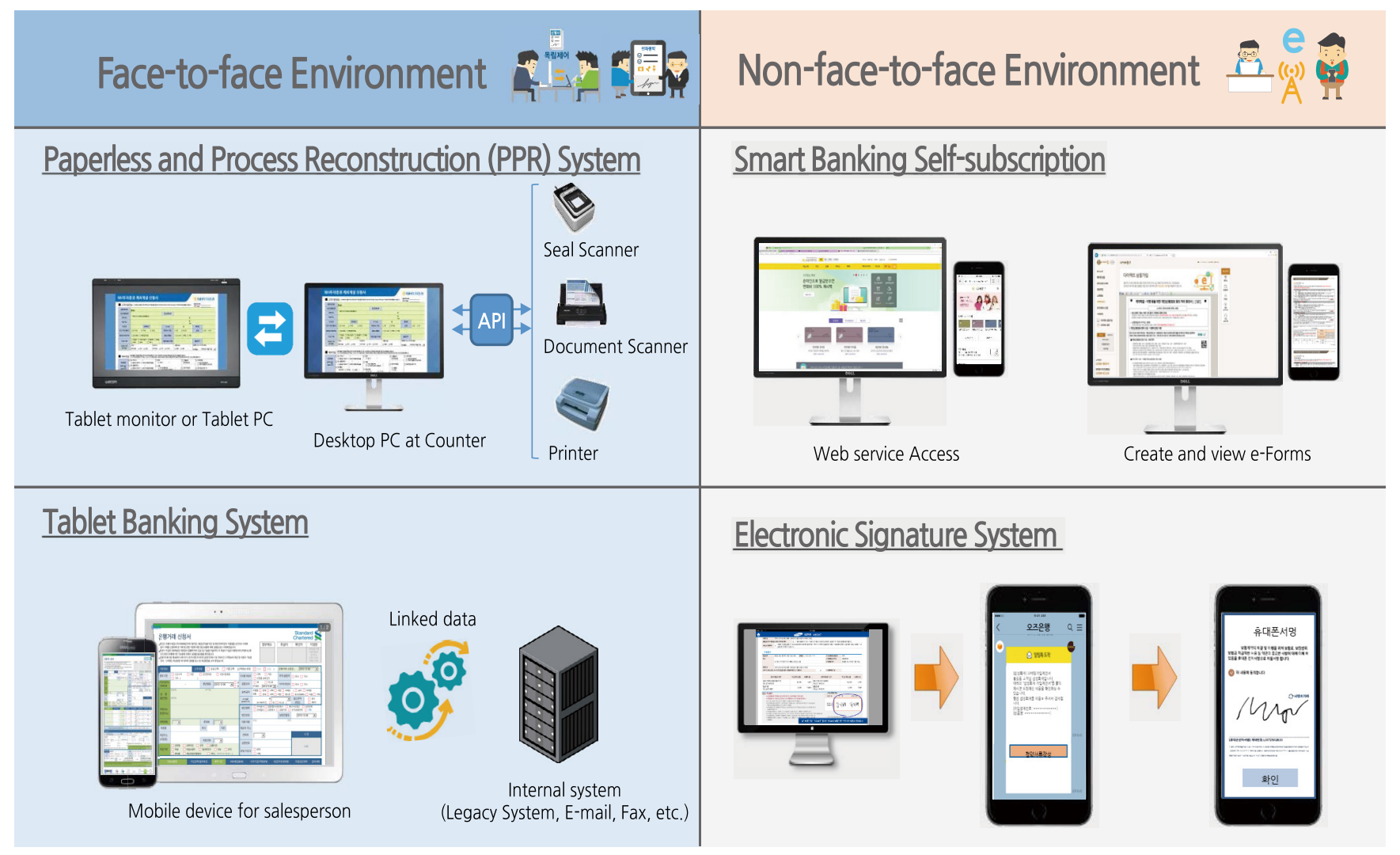

Figure 1. Types of digital banking systems using smart e-Forms. 


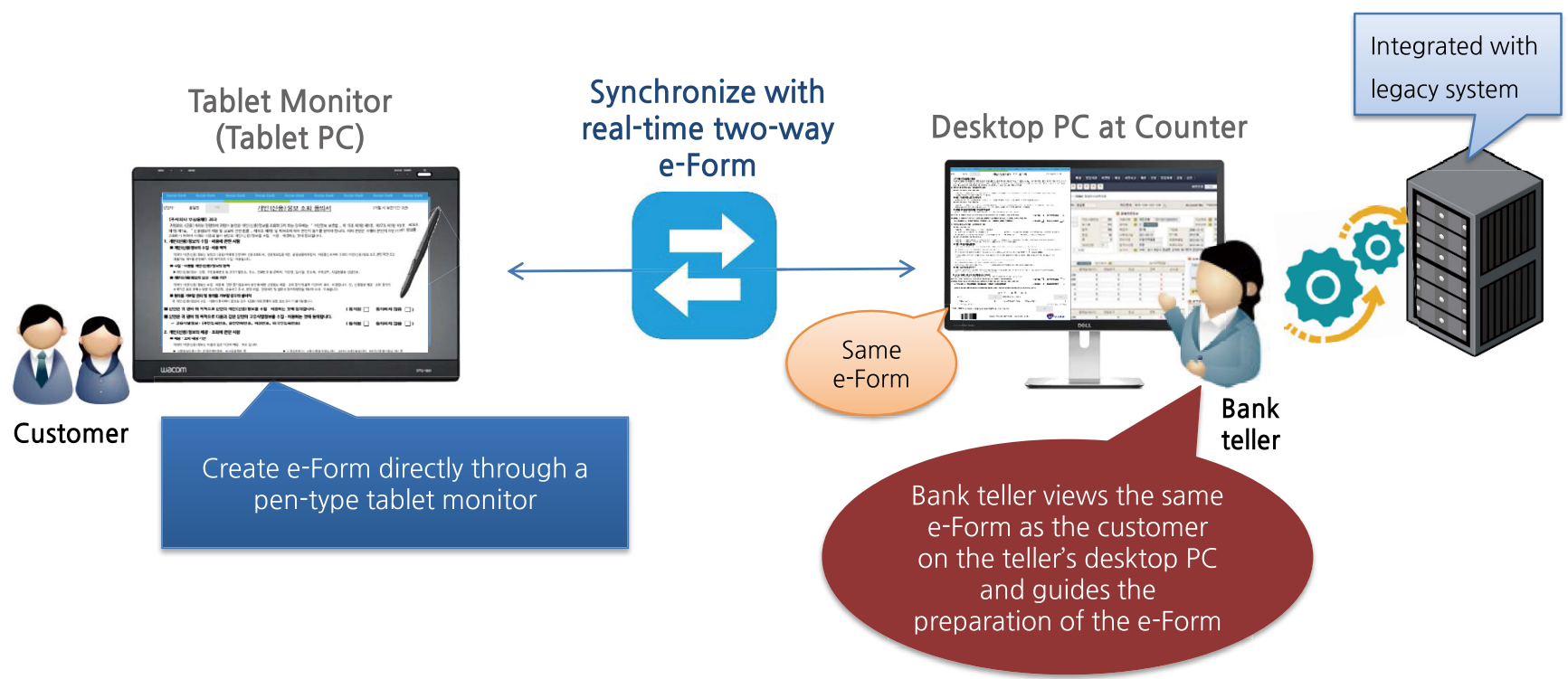

Figure 2. The work process of PPR (paperless and process reconstruction) system.

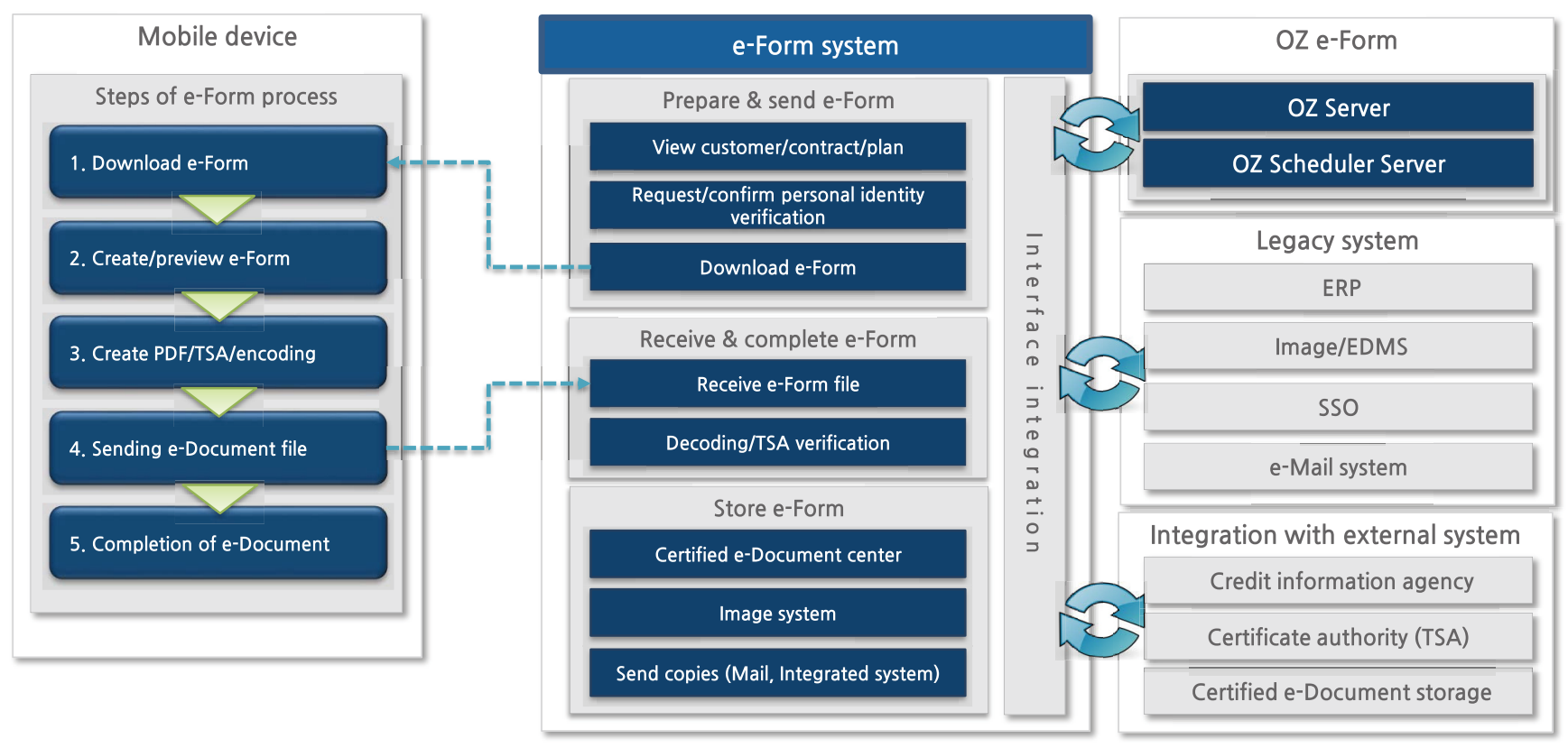

Figure 3. The structure of tablet banking system.

Standard Chartered (SC) Bank's "Banking at your doorstep," customers no longer need to visit branches for financial consultation or product subscription, as bank staff visit customers directly (SC Bank, 2018).

\section{Distance Contract System}

With the explosive growth of smart device use, consumers want instant banking experiences via their smartphones when doing things such as opening a bank account or making a financial transaction. Mobile banking services offer an integrated customer experience of self-directed transactions at their home or office anytime and on any device, allowing them to get things done with a touch of a button. The general process required for the distance contract system is shown in Figure 4.

Using sophisticated mobile banking applications, information security and personal information protection becomes more important because of threats such as hacking and leaking the customer and transaction information. Therefore, smart 


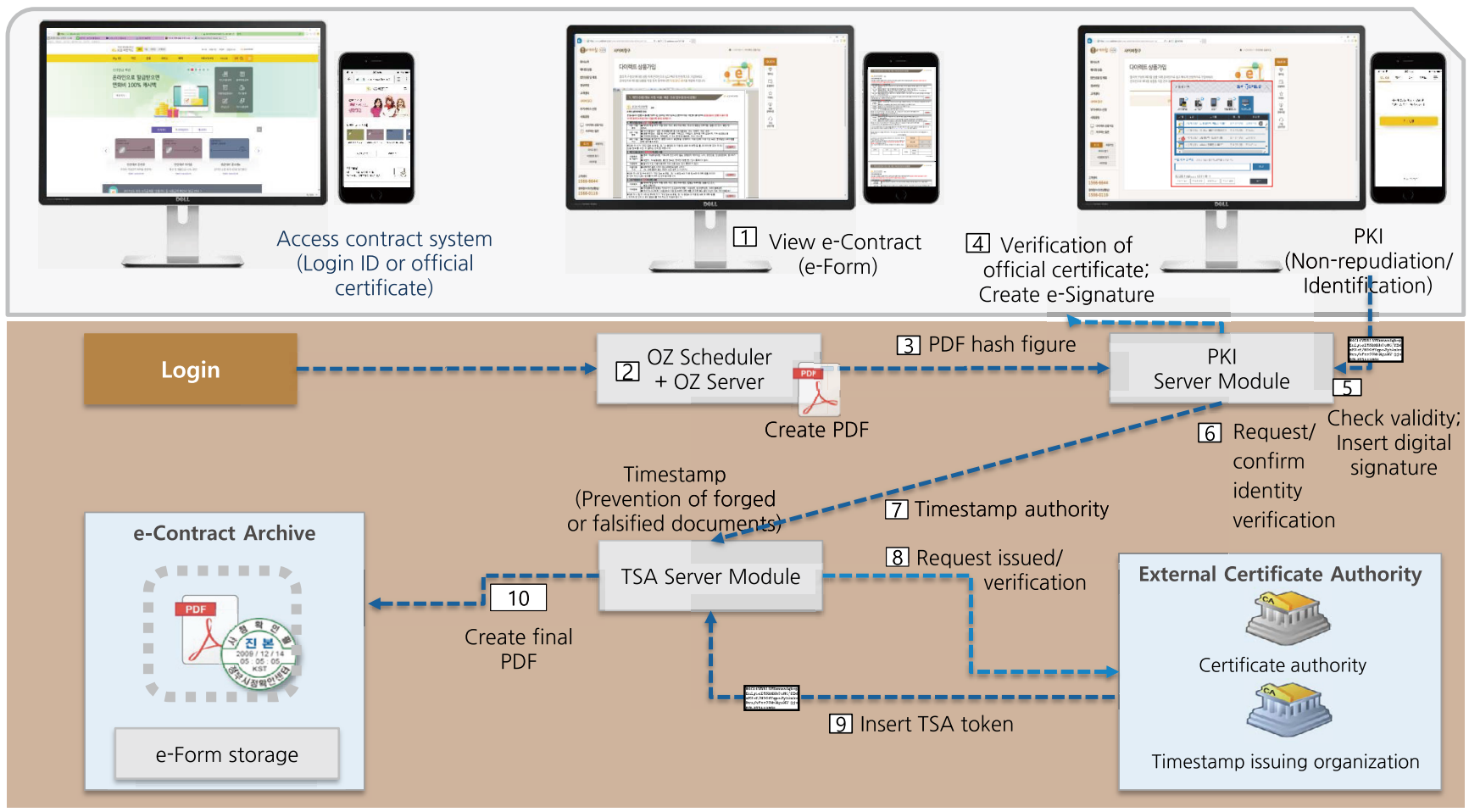

Figure 4. The process of distance contract system.

e-Forms provide a product contract process through smartphone-based electronic signature targeting non-face-to-face customers.

In February 2017, SC Bank (Korea) launched "Self Bank," an application for mobile transactions (Song, 2017). Self Bank is a mobile financial platform that allows customers to sign up for financial products without face-to-face interaction by completing a user authentication process. It is possible to conduct transactions simply by checking the user without an accredited certificate. After the app is installed on the mobile device, the user takes a photo of their ID card and enters basic information. The user verification procedure is completed immediately with customer contact center through a video call.

Another example of the use of smart e-Forms can be found in Prudential's Mobile Insurance Contract System, LiPS (Life Planning Service) (FORCS, 2017). Taking an opportunity to build a distance contract system and a seamless business model for its planners and customers, Prudential Life Insurance (Korea) adopted the OZ Distance Contract solution, which takes care of the entire sales lifecycle from meeting the customer to contract completion. After implementing the system, Prudential significantly increased their business productivity, and customers can now access insurance services at their fingertips.

\section{Discussion}

\section{Benefits of Smart e-Forms}

As the digital environment changes, business communication strategies and paradigms are rapidly evolving. In the financial sector, especially, paperless environments and non-face-to-face mobile banking systems are spreading rapidly due to the emergence of e-Documents, which are considered to be the core of smart business. Based on a systematic review of the impact of digital financial services, the overall performance of firms is promising (Abbasi \& Weigand, 2017). The benefits of adopting digital document-based smart e-Forms that lead these changes are summarized as follows (Burtylev, Mokhun, Bodnya, \& Yukhnevich, 2013):

- The best part of smart e-Form is that customers do not have to be at the bank for a financial transaction, and transactions are recorded in the bank's central server in near real-time. The smart e-Form system can increase work efficiency by improving existing offline business processes such as document receipts, data entry, dispatch, and customer revisits, scanning, typing, and data extraction.

- The system enables us to save costs such as paper and travel expenses and significantly improves productivity by switching from slow offline to fast online work processes. It can also contribute to reduce an institution's carbon footprint. 
- A more complete form of the document can be obtained because digital forms can be validated to ensure there are no errors or missing information. Document security can be strengthened by eliminating the risk of leaking personal information that may occur during the archiving or disposal process of paper documents, preventing forgery of e-Documents and information leakage through the integration of security solutions and secured storage.

- Finally, customer satisfaction can be improved through quick and accurate real-time processing, and customer reliability can be improved by providing repetitive accessing service of e-Documents through the Internet.

\section{Application and Prospect of Smart e-Forms}

FORCS, which developed the OZ e-Form, a smart e-Form solution introduced in this paper, recently provided its tablet banking system to several financial institutions such as Nonghyup Operative Banking, KEB Hana Bank, BNK Busan Bank, City Bank, Jeonbuk Bank, Daegu Charm Savings Bank, Hana Capital, and Hanwha General Insurance. It has also won significant paperless projects from KB Kookmin Bank, Kyongnam Bank, NH Investment \& Securities, Mirae Asset Daewoo, Lotte Card, Shinhan Life, and KB Securities. Furthermore, SC Bank and Prudential Insurance are also operating distance contract systems for non-face-to-face financial services. In particular, SC Bank HQ adopted the OZ e-Form as its global standard solution and is now expanding the "Mobility Platform System" based on the OZ e-Form, which is developed by SC Korea for its branches around the world. The first step projects for 10 countries in Hong Kong, Singapore, Nigeria, UAE, etc. have already been completed, and the second step projects are underway. As such, FORCS's OZ e-Form is growing globally, not only in Korea but also in overseas markets such as Japan, Singapore, Southeast Asia, and China.

As such, FORCS has already carried out projects from many financial institutions and is carrying out many more. The driving forces behind these achievements come from high development productivity and capabilities to cope with diverse customer needs in the financial industry and differentiated technologies with specialized features including various input components. FORCS is expanding its e-Form service business into the software as a service (SaaS) market, which provides a standardized environment and applications based on CLOUD (Common, Location-independent, Online Utility on Demand) (Dermine, 2016). It is also aiming to create new value by combining with artificial intelligence (AI) technology in terms of utilizing and analyzing the data of companies and individuals recorded in e-Documents. FORCS has also been trying to in- crease the value of their system by combining with block chain technology. It is expected that in the way of distributing and storing e-Documents themselves, a close integration or interface between e-Documents and block chain technology can be possible, and there will also be possibilities of interface integration with other information systems or applications as well as implementations of the e-Document system.

\section{Conclusion}

Given the rapid growth of using smart devices and mobile networks, innovative financial services based on digital technology are emerging to support or replace conventional financial services. Financial institutions are building an omnichannel banking experience, offering customers a comprehensive and secure banking experience anytime, anywhere, and across any device. As a functional document format that includes business logic, smart e-Forms have played a major role in innovation in the financial sector. The smart e-Form system improves customer convenience and work efficiency for an adaptive, diversified financial environment. The e-Document-based financial system is strengthening its competitiveness in various ways to lead the Fourth Industrial Revolution.

\section{References}

Abbasi, T., \& Weigand, H. (2017). The impact of digital financial services on firm's performance: A literature review. Retrieved from https://arxiv.org/pdf/1705.10294.pdf

Adobe Korea. (2018, January 23). The fourth industrial revolution, digital innovation in the financial industry starts with big data. Retrieved from https://blogs.adobe.com/digitaldialogue/ko/ customer-experience-ko/digital-transformation-financial-servic es-starts-with-bigdata/

Bae, S. J., \& Ryu, J. H. (2016). Revision of enforcement decree of insurance act and supervision regulation of insurance. Retrieved from http://www.jipyong.com/newsletter/57_201605/data/law3. pdf

BBVA. (2015, March 04). Francisco González: "The future of banking is decided in places like this one". Retrieved from https:// www.bbva.com/en/francisco-gonzalez-the-future-of-banking-isdecided-in-places-like-this-one/

BBVA. (2018, January 25). Francisco González at Davos: "This year, $50 \%$ of our clients will be digital". Retrieved from https://www. bbva.com/en/francisco-gonzalez-davos-this-year-50-our-clientswill-be-digital/

Burtylev, I. N., Mokhun, K. V., Bodnya, Y. V., \& Yukhnevich, D. N. (2013). Development of electronic document management sys- 
tems: Advantage and efficiency. Science and Technology, 3(2A), $1-9$.

Byrnes, N. (2017, February 7). As Goldman embraces automation, even the masters of the universe are threatened. MIT Technology Review. Retrieved from https://www.technologyreview.com/ s/603431/as-goldman-embraces-automation-even-the-mastersof-the-universe-are-threatened/

Dapp, T. F. (2015). Fintech reloaded-Traditional banks as digital ecosystems. Retrieved from https://www.deutschebank. $\mathrm{nl} / \mathrm{nl} /$ docs/Fintech_reloaded_Traditional_banks_as_digital_ ecosystems.pdf

Dasho, A., Meka, E., Sharko, G., \& Baholli, I. (2016). Digital banking the wave of the future. Proceedings of ISTI 2016 (Vol. 1, pp. 1-6). Tirana, Albania.

Dermine, J. (2016). Digital banking and market disruption: A sense of déjà vu? Financial Stability Review, 20. Retrieved from https://faculty.insead.edu/jean-dermine/documents/ BanquedeFrance-DigitalBanking-Proof-2016.pdf

Du Toit, G., \& Burns, M. (2016, November 29). Customer loyalty in retail banking: Global edition 2016. Insight. Retrieved from http://www.bain.com/publications/articles/customer-loyalty-inretail-banking-2016.aspx

FORCS. (2017). Prudential insurance. Retrieved from https://www. forcs.com.sg/case-studies/prudential-insurance

Jung, J. W. (2017, July 11). Citibank's 'store consolidation' 11 branches including Jeju, Gyeongnam, and Ulsan were canceled. Korea JoongAng Daily. Retrieved from https://news.joins.com/ article/21747647

KPMG. (2015, July 2). Mobile banking 2015. Retrieved from https://home.kpmg.com/content/dam/kpmg/pdf/2015/08/ mobile-banking-report-2015.pdf

Lee, S. I. (2017, June 15). Citibank Korea, in effect, 'online bank' ... new internet banking system coming soon. Digital Daily. Retrieved from http://www.ddaily.co.kr/news/article. html?no=157075

Lee, S. I. (2018, January 29). KEB Hana Bank conducts artificial intelligence service "HAI banking" in 'Hana Members'. Digital Daily. Retrieved from http://www.ddaily.co.kr/news/article. html?no=165169

Lee, S. W., Song, K. H., \& Park, E. R. (2017, April 9). The war of $\mathrm{K}$ : K bank combined with KT and GS25 vs. Kakao talk's Kakao Bank. Yonhap News. Retrieved from http://www.yonhapnews. co.kr/bulletin/2017/04/06/0200000000AKR20170406158300002. HTML

Opensignal. (2018). The state of LTE (February 2018). Retrieved from https://opensignal.com/reports/2018/02/state-of-lte

SC Bank. (2018). Banking at your doorstep. Retrieved from https:// www.standardchartered.co.kr/np/en/pl/wb/EnVisitbankingGuide. jsp?ptfrm=HIN.ENG.INTROPC.fotbanner2

SciPol. (2017, February 27). Goldman sacked: How artificial intelligence will transform wall street. Retrieved from http://scipol. duke.edu/content/goldman-sacked-how-artificial-intelligence-wi 1l-transform-wall-street

Song, K. H. (2017, February 14). SC First Bank launches non-faceto-face transaction 'Self Bank'. Yonhap News. Retrieved from http://www.yonhapnews.co.kr/bulletin/2017/02/14/0200000000 AKR20170214044700002.HTML 